\title{
The first detection of species of Babesia Starcovici, 1893 in moose, Alces alces (Linnaeus), in Norway
}

\author{
Irma Pūraitė ${ }^{1}$, Olav Rosef ${ }^{1,2}$, Jana Radzijevskaja $^{1}$ Indrė Lipatova $^{1}$ and Algimantas Paulauskas ${ }^{1}$
}

${ }^{1}$ Vytautas Magnus University, Kaunas, Lithuania;

${ }^{2}$ Rosef field research station, Mjåvatn, Norway

\begin{abstract}
Babesiosis is an emerging zoonotic disease and various wildlife species are reservoir hosts for zoonotic species of Babesia Starcovici, 1893. The objective of the present study was to investigate the presence and prevalence of Babesia spp. in moose Alces alces (Linnaeus) in two regions of Norway. A total of 99 spleen samples were collected from animals of various ages from an area with the occurrence of the tick Ixodes ricinus (Linnaeus, 1758), and from an area where the ticks are known to be absent. Infection was detected by the amplification of different regions of the 18S rRNA gene by using two different PCR primer sets specific of Babesia. Babesia spp. were found in the spleen samples of four moose. All Babesia-infected animals were from an area where ticks occur, with an infection rate of 6\% (4 of 70). Babesia-positive samples were obtained from a five-month old moose calf and three adults. Two Babesia species, Babesia capreoli (Enigk et Friedhoff, 1962) and a B. odocoilei-like, were identified. Co-infection with Anaplasma phagocytophilum was obtained in two animals. This is the first report of the occurrence of $B$. capreoli and B. odocoilei-like species in moose.
\end{abstract}

Keywords: Babesia capreoli, Babesia odocoilei-like, 18S rRNA gene, Ixodes ricinus, zoonosis

Ticks and tick-borne diseases in Europe have recently shown expansion in their distribution (Gray et al. 2009). Climatic and environmental changes are affecting the habitats and the structure of wildlife populations and are important drivers of tick population dynamics and geographic distribution. The tick Ixodes ricinus (Linnaeus, 1758) has been shown to be involved in the transmission of a range of zoonotic pathogens such as tick-borne encephalitis virus, bacteria causing Lyme disease and granulocytic anaplasmosis in humans and animals, as well as blood parasites such as intraerythrocytic species of Babesia Starcovici, 1893. Babesiosis is a worldwide tick-borne hemoprotozoosis caused by intraerythrocytic protozoan parasites of the genus Babesia. The parasites infect red blood cells of vertebrate hosts and are transmitted by ixodid ticks. In Europe, babesiosis has been reported both in humans and some domestic and free-living mammals (Herwaldt et al. 2003). In Norway, one case of severe human babesiosis due to Babesia divergens (M'Fadyean et Stockman, 1911) has been documented, and seroprevalence of this species in cattle is known to be high (Hasle et al. 2010, Mørch et al. 2015).

To date, four species of Babesia have been described from wild European cervids: B. venatorum Herwaldt, Cacciò, Gherlinzoni, Aspöck, Slemenda, Piccaluga, Martinelli, Edelhofer, Hollenstein, Poletti, Pampiglione, Löschenberger, Tura et Pieniazek, 2003 (first known as Babesia sp. EU1; Herwaldt et al. 2003), B. divergens, B. capreoli (Enigk et Friedhoff, 1962) and B. odocoilei-like (Duh et al. 2005, Bonnet et al. 2007a, Malandrin et al. 2010, Silaghi et al. 2011, Zintl et al. 2011, Zanet et al. 2014). Babesia venatorum has been identified in roe deer, Capreolus capreolus (Linnaeus) (Duh et al. 2005, Bonnet et al. 2007a). Babesia divergens and $B$. capreoli have been reported from roe deer, red deer, Cervus elaphus Linnaeus, reindeer, Rangifer tarandus (Linnaeus), alpine chamois, Rupicapra rupicapra (Linnaeus), and alpine ibex, Capra ibex (Linnaeus) (Langton et al. 2003, Malandrin et al. 2010, Zintl et al. 2011, Michel et al. 2014). However, the possible role of moose, Alces alces (Linnaeus), as a reservoir for Babesia spp. remains unknown. The aim of the present study was thus to investigate the occurrence and the diversity of Babesia spp. in moose to assess the role of this cervid as a possible reservoir for zoonotic babesiosis.

\section{MATERIALS AND METHODS}

Spleen samples from 99 moose of different ages and sex were collected during the hunting seasons in 2013 and 2014 in AustAgder County $(\mathrm{n}=70)$, an area where Ixodes ricinus ticks are present, and Oppland County $(\mathrm{n}=29)$, an area where ticks are known to be absent. All spleen samples were kept frozen at $-20^{\circ} \mathrm{C}$ until analysed.

DNA from the spleens was extracted with the Genomic DNA Purification Kit K0512 (Thermo Fisher Scientific Baltics, Vilni- 
Table 1. PCR conditions and primers used for the detection of Babesia spp.

\begin{tabular}{|c|c|c|c|c|c|c|c|}
\hline Primer & & Gene (bp) & Ds & As & Es & Cycles & Reference \\
\hline $\begin{array}{l}1^{\text {st }} \text { protocol } \\
\text { BS1 } \\
\text { 5'-GACGGTAGGGTATTGGCCT } \\
\text { BS2 } \\
\text { 5'-ATTCACCGGATCCACTCGATC }\end{array}$ & External & $\begin{array}{l}\text { 18S rRNA } \\
\text { (1304 bp) }\end{array}$ & $\begin{array}{l}94^{\circ} \mathrm{C} \\
1 \mathrm{~min}\end{array}$ & $\begin{array}{l}58^{\circ} \mathrm{C} \\
1 \mathrm{~min}\end{array}$ & $\begin{array}{c}72^{\circ} \mathrm{C} \\
1 \mathrm{~min} 30 \mathrm{~s}\end{array}$ & 35 & Rar et al. 2005, 2011 \\
\hline $\begin{array}{l}\text { PiroA } \\
\text { 5'-ATTACCCAATCCTGACACAGGG } \\
\text { PiroC } \\
\text { 5'-CCAACAAAATAGAACCAAAGTCCTAC }\end{array}$ & Internal & $\begin{array}{l}\text { 18S rRNA } \\
(380 \mathrm{bp})\end{array}$ & $\begin{array}{l}94^{\circ} \mathrm{C} \\
1 \mathrm{~min}\end{array}$ & $\begin{array}{l}64^{\circ} \mathrm{C} \\
1 \mathrm{~min}\end{array}$ & $\begin{array}{c}72^{\circ} \mathrm{C} \\
1 \mathrm{~min} 30 \mathrm{~s}\end{array}$ & 35 & $\begin{array}{l}\text { Armstrong et al. 1998, } \\
\text { Rar et al. } 2011\end{array}$ \\
\hline $\begin{array}{l}2^{\text {nd }} \text { protocol } \\
\text { Babfor } \\
\text { 5'-GACTAGGGATTGGAGGTC } \\
\text { Babrev } \\
\text { 5'-GAATAATTCACCGGATCACTC }\end{array}$ & External & $\begin{array}{c}\text { 18S rRNA } \\
(652 \mathrm{bp})\end{array}$ & $\begin{array}{l}95^{\circ} \mathrm{C} \\
1 \mathrm{~min}\end{array}$ & $\begin{array}{c}53^{\circ} \mathrm{C} \\
1 \mathrm{~min} 30 \mathrm{~s}\end{array}$ & $\begin{array}{c}72^{\circ} \mathrm{C} \\
1 \mathrm{~min} 30 \mathrm{~s}\end{array}$ & 35 & Zintl et al. 2011 \\
\hline $\begin{array}{l}\text { BT2-F } \\
\text { 5'-GGAGTATGGTCGCAAGTCTG } \\
\text { Babrev } \\
\text { 5'-GAATAATTCACCGGATCACTC }\end{array}$ & Internal & $\begin{array}{l}\text { 18S rRNA } \\
(576 \mathrm{bp})\end{array}$ & $\begin{array}{l}95^{\circ} \mathrm{C} \\
1 \mathrm{~min}\end{array}$ & $\begin{array}{c}53^{\circ} \mathrm{C} \\
1 \mathrm{~min} 30 \mathrm{~s}\end{array}$ & $\begin{array}{c}72^{\circ} \mathrm{C} \\
1 \mathrm{~min} 30 \mathrm{~s}\end{array}$ & 35 & Zintl et al. 2011 \\
\hline
\end{tabular}

Ds - denaturation step; As - annealing step; Es - elongation step.

us, Lithuania) according to the manufacturer's instructions. To examine the presence of Babesia-DNA, two nested PCR protocols targeting different regions of the 18S rRNA gene were used (Table 1). Amplification was performed using the Mastercycler thermocycler (Eppendorf, Hamburg, Germany). Positive and negative controls were included in each PCR run. Amplification products were separated by electrophoresis on $1.5 \%$ agarose gel, stained with GelRed ${ }^{\mathrm{TM}}$ DNA-staining reagent (Biotium, Hayward, USA) and visualised under ultraviolet light.

PCR-positive samples were confirmed by DNA sequencing of the partially amplified 18S rRNA gene of Babesia spp. Amplicons were cut out from agarose gel and purified using the GeneJET Gel Extraction Kit K0691 (Thermo Fisher Scientific Baltics). Forward primers for amplification were used as sequencing primers. Chromatograms were manually edited and trimmed prior to assembly. Nucleotide sequences were identified by the Basic Local Alignment Search Tool at the National Centre for Biotechnology Information using MEGA 6 software (Tamura et al. 2013).

A phylogenetic tree was constructed from the sequences of the 18S rRNA gene of Babesia spp. identified in the present study and those available from GenBank using the neighbour-joining method (Saitou and Nei 1987) with a bootstrap analysis of 1000 replicates in MEGA 6. The partial nucleotide sequences of the Babesia spp. 18S rRNA gene were added to the GenBank database under the accession numbers: KT279879-KT279886.

\section{RESULTS}

Babesia spp. were found in four samples of moose spleens. All Babesia-infected animals were from the area where the tick Ixodes ricinus is present (Aust-Agder County; i.e. 4 of 70 , prevalence 6\%). Babesia-positive samples were obtained from a five-month old moose calf and three adults. The prevalence of Babesia spp. in Oppland County was $0 \%(\mathrm{n}=26)$.

Species of Babesia were identified by sequence-analysis of fragments amplified using both PCR protocols (Table 1). According to the $1^{\text {st }} \mathrm{PCR}$ protocol, $18 \mathrm{~S}$ rDNA sequences (5' end of $18 \mathrm{~S}$ rDNA region) derived from three Babe-

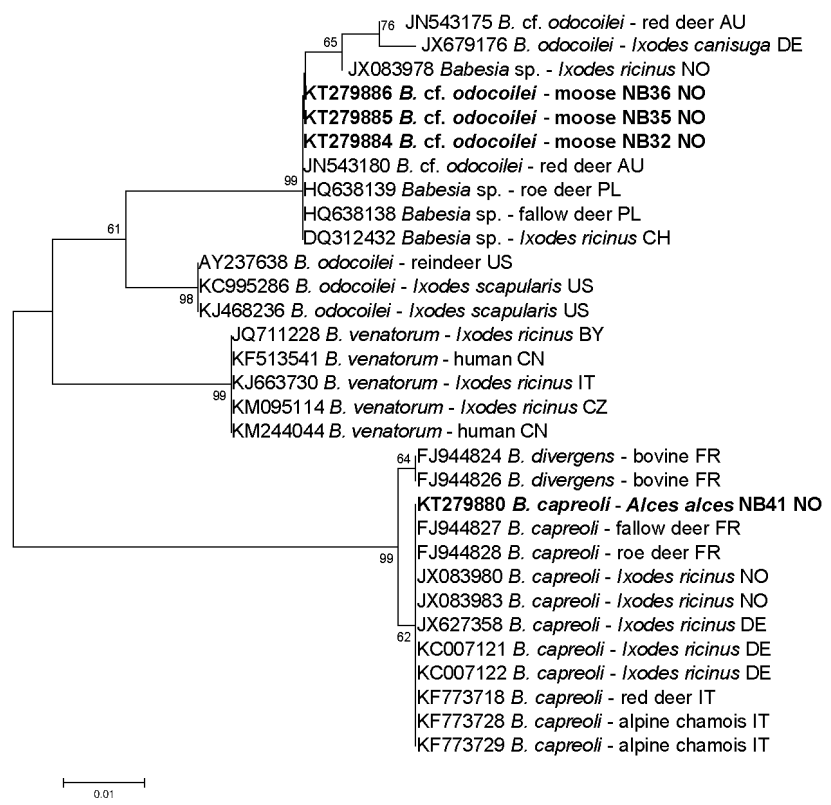

Fig. 1. Phylogenetic relationship of species of Babesia (samples from the present study bolded). Abbreviations: AU - Austria, BY - Belarus, CH - Switzerland, CN - China, CZ - Czech Republic, DE - Germany, FR - France, IT - Italy, NO - Norway, PL - Poland, US - United States of America.

sia-positive samples (isolates NB32, NB35 and NB36) were designated as $B$. odocoilei-like (Fig. 1). The sequences were identical to each other and showed $100 \%$ similarity to a sequence of Babesia cf. odocoilei (Emerson et Wright, 1970) (GenBank Accession No. JN543180) and to an unidentified species of Babesia (Babesia sp., GenBank Accession No. HQ638138) from red deer in Austria and Ireland, respectively (Fig. 1). These sequences were also identical to Babesia sp. from ticks feeding on red deer in Switzerland, which was previously described as a novel Babesia sp. genotype CH1 (GenBank Accession No. DQ312432) closely related to $B$. odocoilei reported from North Amer- 
Table 2. Identification of species of Babesia species in moose from Norway.

\begin{tabular}{|c|c|c|c|c|}
\hline Sample ID & GenBank ID 5'-end & GenBank ID 3'-end & Identified according to $1^{\text {st }}$ protocol & Identified according to $2^{\text {nd }}$ protocol \\
\hline NB32 & KT279884 & KT279881 & $100 \%$ identical with $B$. cf. odocoilei & $97 \%$ identical with $B$. odocoilei, $B$. venatorum \\
\hline NB35 & KT279885 & KT279882 & $100 \%$ identical with $B$. cf. odocoilei & $97 \%$ identical with $B$. odocoilei, $B$. venatorum \\
\hline NB36 & KT279886 & KT279883 & $100 \%$ identical with $B$. cf. odocoilei & $97 \%$ identical with $B$. odocoilei, $B$. venatorum \\
\hline NB41 & KT279880 & KT279879 & $100 \%$ identical to B. capreoli & $100 \%$ identical with $B$. capreoli, B. divergens \\
\hline
\end{tabular}

ica. Sequence analysis of the remaining sequence (isolate NB41) revealed $100 \%$ identity to B. capreoli (GenBank Accession Nos. KF773728, KF773729, JX083980).

According to the $2^{\text {nd }}$ PCR protocol , BLAST search on 3 ' end of $18 \mathrm{~S}$ rDNA region revealed a $100 \%$ similarity of isolates NB32, NB35 and NB36 with Babesia sp. derived from the tick $I$. ricinus in Norway (GenBank Accession No. JX042313) and Babesia sp. from red deer in Ireland (GenBank Accession No. GU475475). These sequences showed a $97 \%$ similarity with $B$. odocoilei described from elk (C. elaphus canadensis Erxleben) in Canada. Analysis of the sequence of NB41 sample of this region revealed a $100 \%$ similarity with $B$. divergens (GenBank Accession No. JX042324, JX042329 and GQ304524-5) and B. capreoli (GenBank Accession No. GQ304526 and FJ944827-8) as this region of $18 \mathrm{~S}$ rDNA is identical for both species.

\section{DISCUSSION}

Species of Babesia are among the most common hemoparasites in the world (Yabsley and Shock 2013). These parasites have a wide host range, including hundreds of species of mammals. Humans can serve as accidental hosts for numerous species of Babesia (see Yabslei and Shock 2013). Transovarial transmission of some Babesia spp has been documented in Ixodes ricinus (see Bonnet et al. 2007b, 2009).

Ixodes ricinus is ubiquitous in southern Norway with the highest density near the coast (Mehl 1983, Jore et al. 2011). During the past decades, tick abundance has increased and its distribution area expanded further north and to higher altitudes (Jore et al. 2011, Medlock et al. 2013, Jore et al. 2014). The overall prevalence of Babesia spp. in questing $I$. ricinus ticks in Norway was $0.9 \%$ and several species such as $B$. venatorum, $B$. divergens, $B$. capreoli and Babesia sp. were identified (Radzijevskaja et al. 2008, Øines et al. 2012).

We detected a relatively low prevalence of DNA of Babesia spp. in moose spleen if compared with what was previously observed in red deer (from $11 \%$ in Switzerland to $47 \%$ in Ireland) and roe deer (from $9 \%$ in Spain to $7 \%$ in Slovenia) (Silaghi et al. 2011).

Although initially specificity of Babesia spp. for the vertebrate host was described as restricted, the development of molecular tools allowed detecting some species of Babesia in a wider range of vertebrate hosts than was thought previously (Chauvin et al. 2009). Babesia divergens was originally described as a parasite of cattle in temperate regions, but later was identified in splenectomised humans, ungulates such as roe deer, red deer, fallow deer, moufflon and non-splenectomised rein deer and sheep (Chauvin et al. 2009). The ability of merozoites of Babesia spp. to invade erythrocytes from a wide range of animal species was demonstrated in experimental studies and suggested possibilities for these parasites to adapt and develop in new hosts (Chauvin et al. 2009). Ixodes ricinus ticks parasitise on a wide range of vertebrate hosts and could harbour/carry $B$. divergens, $B$. venatorum, $B$. capreoli and B. odocoilei-like species (Øines et al. 2012), thus providing possibilities for efficient transmission of these Babesia spp. to new potential hosts such as moose.

The evolution of new strains or species of Babesia depends on the capacity of particular species of Babesia to develop in a new host. Babesia spp. have developed strategies to avoid the immune response, which enables them to survive inside the vertebrate host. The humoral immune response studied for some of Babesia spp., B. ovis (Babes, 1892), B. divergens, B. canis (Piana et Galli-Valerio, 1895) or B. gibsoni (Patton, 1910), showed the production of antibodies beginning approximately 7 days after infection and persisting for several months (Chauvin et al. 2009).

In the present study, we used two different PCR protocols. The alignment of $410 \mathrm{bp}$ sequences in the $3^{\prime}$ end of $18 \mathrm{~S}$ rDNA of Babesia ( $2^{\text {nd }}$ protocol, Table 1) showed that the sequence of NB41 individual is identical to those of $B$. divergens and $B$. capreoli. The differentiation between $B$. capreoli and $B$. divergens is difficult due to their morphological similarities and it is also complicated due to the high percentage of identity between the sequences of their respective 18S rRNA genes (Lempereur et al. 2012). In this study, identification of $B$. capreoli was based on the difference of two nucleotide bases on the amplified fragment of the 18S rRNA gene at positions 631 and 663 (Malandrin et al. 2010; Table 2).

Babesia capreoli was identified in the spleen of one moose (NB41, Fig. 1). This species is known to circulate among wild cervids with silent babesiosis (Penzhorn 2006). Babesiosis caused by $B$. capreoli in humans or livestock remains unknown (Malandrin et al. 2010). To the best of our knowledge, $B$. capreoli infection has not been previously reported in moose. We detected $B$. odocoileilike species in three moose, which is the first detection of this species in moose. Babesia odocoilei is a parasite of North-American white-tailed deer, Odocoileus virginianus (Zimmermann), elk and caribou, $R$. tarandus caribou (Linnaeus), transmitted by ticks, Ixodes scapularis Say, 1821 (Holman et al. 2000). In Europe, Babesia sp. closely related to this parasite has been detected in I. ricinus and red deer was suggested as a possible reservoir (Duh et al. 2001, Herwaldt et al. 2003, Hilpertshauser et al. 2006, Zintl et al. 2011, Øines et al. 2012).

The pathogenicity of Babesia spp. differs between ungulate species. The occurrence of silent Babesia spp. in- 
fection in free-ranging cervids has been demonstrated in numerous studies, and it has been suggested that clinical babesiosis is rarely observed in wild ruminants (Penzhorn 2006). Fatal babesiosis due to $B$. divergens/B. capreoli-like infection has been described in chamois (Hoby et al. 2009).

Several recently published reports have indicated that Babesia infection due to $B$. capreoli and $B$. venatorum may have contributed to the mortality of roe deer, reindeer and alpine chamois (Kik et al. 2011, Michel et al. 2014). Severe infections and Babesia-related mortalities were found in reindeer due to $B$. divergens and $B$. odocoilei (see Langton et al. 2003, Barlett et al. 2009). However, it was noted that wild animals such as reindeer, when removed from their natural habitats (where babesiosis is not endemic) and placed in captivity in non-native areas, are not adapted to Babesia parasites, and therefore may become severely infected and demonstrate clinical signs of babesiosis (Penzhorn 2006).

All 99 spleen samples of moose were also screened for Anaplasma phagocytophilum in another study (Pūraitè et al. 2015). Co-infection with $A$. phagocytophilum was recorded in two of the four moose, which were positive for Babesia spp. Both of the co-infected animals harboured $B$. odocoilei-like species. We thus conclude that moose may play a certain role in the circulation of $B$. capreoli and B.odocoilei-like species in Norway.

Acknowledgements. We thank hunters in Aust-Agder and Øystre Slidre for providing samples.

\section{REFERENCES}

Armstrong P.M., Katavolos P., Caporale D.A., Smith R.P., Spielman A., Telford S.R. 3rd. 1998: Diversity of Babesia infecting deer ticks (Ixodes dammini). Am. J. Trop. Med. Hyg. 58: 739-742.

Barlett S.L., Abou-Madi N., Messick J.B., Birkenheuer A., Kollias G.V. 2009: Diagnosis and treatment of Babesia odocoilei in captive reindeer (Rangifer tarandus tarandus) and recognition of three novel host species. J. Zoo. Wildl. Med. 40: $152-159$.

Bonnet S., Brisseau N., Hermouet A., Jouglin M., ChauVIN A. 2009: Experimental in vitro transmission of Babesia sp. (EU1) by Ixodes ricinus. Vet. Res. 40: 21.

Bonnet S., Jouglin M., L'Hostis M., Chauvin A. 2007a: Babesia $\mathrm{sp}$. EU1 from roe deer and transmission with Ixodes ricinus. Emerg. Infect. Dis. 13: 1208-1210.

Bonnet S., Jouglin M., Malandrin L., Becker C., AgouLON A., L'Hostis M., Chauvin A. 2007b: Transstadial and transovarial persistence of Babesia divergens DNA in ticks fed on infected blood in a new skin-feeding technique. Parasitology 134: 197-207.

Chauvin A., Moreau E., Bonnet S., Plantard O., MalanDRIN L. 2009: Babesia and its hosts: adaptation to long-lasting interactions as a way to achieve efficient transmission. Vet. Res. 40: 37.

Duh D., Petrovec M., AvŠIČ-Županc T. 2001: Diversity of Babesia infecting European sheep ticks (Ixodes ricinus). J. Clin. Microbiol. 39: 3395-3397.

Duh D., Petrovec M., Bidovec A., Avšič-Županc T. 2005 : Cervids as babesiae hosts, Slovenia. Emerg. Infect. Dis. 11: 1121-1123.

Gray J.S., Dautel H., Estrada-Peña A., Kahl O., Lindgren E. 2009: Effects of climate change on ticks and tick-borne diseases in Europe. Interdiscip. Perspect. Infect. Dis. 2009: 593232

Hasle G., Buune G.A., Christensson D., Røed K.H., Whist A.C., LeinaAs H.P. 2010: Detection of Babesia divergens in southern Norway by using an immunofluorescence antibody test in cow sera. Acta Vet. Scand. 52: 55.

Herwaldt B.L., Caccio S., Cherlinzoni F., Aspöck H., Slemenda S.B., Piccaluga P., Martinelli G., Edelhofer R., Hollenstein U., Poletti G., Pampiglione S., Löschenberger K., Tura S. Pieniazek N.J. 2003: Molecular charachterization of a non-Babesia divergens organism causing zoonotic babesiosis in Europe. Emerg. Infect. Dis. 9: 942-948.

Hilpertshauser H., Deplazes P., Schnyder M., Gern L., MaTHIS A. 2006: Babesia spp. identified by PCR in ticks collected from domestic and wild ruminants in southern Switzerland. Appl. Environ. Microbiol. 72: 6503-6507.

Hoby S., Mathis A., Doherr M.G., Robert N., Ryser-DegiorGIS M.P. 2009: Babesia capreoli infections in Alpine chamois
(Rupicapra r. rupicapra), roe deer (Capreolus c. capreolus) and red deer (Cervus elaphus) from Switzerland. J. Wildl. Dis. 45: $748-753$.

Holman P.J., Madeley J., Craig T.M., Allsopp B.A., AllSopp M.T., Petrini K.R., Wagheia S.D., Wagner G.G. 2000: Antigenic, phenotypic and molecular characterization confirms Babesia odocoilei isolated from three cervids. J. Wildl. Dis. 36: 518-530.

Jore S., Vanwambeke S.O., Viluugrein H., Isaksen K., Kristoffersen A.B., Woldehiwet Z., Johansen B., Brun E., Brun-Hansen H., Westermann S., Larsen I.L., Ytrehus B., Hofshagen M. 2014: Climate and environmental change drives Ixodes ricinus geographical expansion at the northern range margin. Parasit. Vectors 7: 11.

Jore S., Viljugrein H., Hofshagen M., Brun-Hansen H., Kristoffersen A.B., NygÅrd K., Brun E., Ottesen P., SÆVIK B.K., Ytrehus B. 2011: Multi-source analysis reveals latitudinal and altitudinal shifts in range of Ixodes ricinus at its northern distribution limit. Parasit. Vectors 4: 84.

Kik M., Nijhof A.M., Balk J.A., Jongejan F. 2011: Babesia sp. EU1 infection in a forest reindeer, the Netherlands. Emerg. Infect. Dis. 17: 936-938.

Langton C., Grey J.S., Waters P.F., Holman P.J. 2003: Naturally acquired babesiosis in a reindeer (Rangifer tarandus taran$d u s$ ) herd in Great Britain. Parasitol. Res. 89: 194-198.

Lempereur L., Wirtgen M., Nahayo A., Caron Y., Shiels B., Saegerman C., Losson B., Linden A. 2012: Wild cervids are host for tick vectors of Babesia species with zoonotic capability in Belgium. Vector Borne Zoonotic Dis. 12: 275-280.

Malandrin L., Jouglin M., Sun Y., Brisseau N., Chauvin A. 2010: Redescription of Babesia capreoli (Enigk and Friedhof, 1962) from roe deer (Capreolus capreolus): isolation, cultivation, host specificity, molecular characterization and differentiation from Babesia divergens. Int. J. Parasitol. 40: 277-284.

Medlock J.M, Hansford K.M., Bormane A., Derdakova M., Estrada-Peña A., George J.C., Golovljova I., Jaenson T.G.T., Jensen J.K., Jensen P.M, Kazimirova M., Oteo J.A., Papa A., Pfister K., Plantard O., Randolph S.E., Rizzoli A., Santos-Silva M.M., Sprong H., Vial L., HenDRICKX G., Zeller H., VAN Bortel W. 2013: Driving forces for change in geographical distribution of Ixodes ricinus in Europe. Parasit. Vectors 6: 1 .

MenL R. 1983: The distribution and host relations of Norwegian ticks (Acari, Ixodides). Fauna Norv. Ser. B 30: 46-51.

Michel A.O., Mathis A., Ryser-Degeorgis M.P. 2014: Babesia spp. in European wild ruminant species: parasite diversity and risk factors for infection. Vet. Res. 45: 65 
Mørch K., Holmaas G., Frolander P.S., Kristoffersen E.K. 2015: Severe human Babesia divergens infection in Norway. Int. J. Infect. Dis. 33: 37-38.

Øines Ø., Radzijevskaja J., Paulauskas A., Rosef O. 2012 Prevalence and diversity of Babesia spp. in questing Ixodes ricinus ticks from Norway. Parasit. Vectors 5: 156.

PEnZhorn B.L. 2006: Babesiosis of wild carnivores and ungulates. Vet. Parasitol. 138: 11-21.

Pūraité I., Rosef O., Paulauskas A., Radzijevskaja J. 2015: Anaplasma phagocytophilum infection in moose (Alces alces) in Norway. Microbes Infect. 17: 823-828.

Radzijevskaja J., Paulauskas A., Rosef O. 2008: Prevalence of Anaplasma phagocytophilum and Babesia divergens in Ixodes ricinus ticks from Lithuania and Norway. Int. J. Med. Microbiol. 298 (S1): 218-221.

Rar V.A., Epikhina T.I., Livanova N.N., Panov V.V. 2011: Genetic diversity of Babesia in Ixodes persulcatus and small mammals from North Ural and West Siberia, Russia. Parasitology 138: $175-182$.

Rar V.A., Fomenko N.V., Dobrotvorsky A.K., Livanova N.N., Rudakova S.A., Fedorov E.G., Astanin V.B., Moro- zova O. 2005: Tickborne pathogen detection, Western Siberia, Russia. Emerg. Infect. Dis. 11: 1708-1715.

Saitou N., NeI M. 1987: The neighbour-joining method for reconstructing phylogenetic trees. Mol. Biol. Evol. 4: 406-425.

Silaghi C., Hamel D., Pfister K., Rehbein S. 2011: Babesia species and co-infection with Anaplasma phagocytophilum in free-ranging ungulates from Tyrol (Austria). Wien Tierärztl. Mschr.-Vet. Med. Austria. 98: 268-274.

Tamura K., Stecher G., Peterson D., Filipski A., Kumar S. 2013: MEGA:6 Molecular evolutionary genetics analysis version 6.0. Mol. Biol. Evol. 30: 2725-2729.

YabSley M.J., Shock B.C. 2013: Natural history of zoonotic Babesia: role of wildlife reservoirs. Int. J. Parasitol. Parasites Wildl. 2: 18-31.

Zanet S., Trisciuoglio A., Bottero E., Fernandez de Mera G.I., Gortazar C., Carpignano M.G., Ferroglio E. 2014: Piroplasmosis in wildlife: Babesia and Theileria affecting free-ranging ungulates and carnivores in the Italian Alps. Parasit. Vectors 7: 70.

Zintl A., Finnerty E.J., Murphy T.M., de Wahl T., Gray J.S. 2011: Babesias of red deer (Cervus elaphus) in Ireland. Vet. Res. 42: 7 . 